\title{
Epithelial hyperplasia and malignant change in congenital lung cysts
}

\author{
E A SHEFFIELD, B J ADDIS, B CORRIN, MARY M MCCABE
}

From the Departments of Histopathology, Brompton Hospital, London, and St Vincent's Hospital, Dublin

SUMMARY Patients with congenital lung cysts are at increased risk of developing carcinoma, but the mechanisms concerned are not clear. The case of a young adult who developed a bronchioloalveolar carcinoma associated with a cystic congenital adenomatoid malformation is reported. The adjacent lung showed an unusual intra-alveolar hyperplasia of mucous cells. Two further cases of congenital adenomatoid malformation are also described; both patients presented in infancy and showed similar mucous cell hyperplasia in alveoli surrounding the cysts. In all three cases the staining characteristic of the mucus was identical with that of normal bronchial mucous glands. It is suggested that the benign proliferation represents a premalignant lesion. Its presence in infants shows that it may occur at an early age and reinforces the need for early removal of congenital lung cysts.

A number of reports have described the development of malignancy in association with congenital lung cysts. ${ }^{1-8}$ Adenocarcinoma is the most common type of tumour, often of bronchioloalveolar pattern, but squamous cell carcinoma has also been reported. ${ }^{78}$ Squamous metaplasia of the lining epithelium of congenital cysts has been implicated as the precursor lesion in the development of squamous cell carcinoma in some cases, ${ }^{9}$ but the mechanisms implicated in the development of other tumour types are not clear.

We describe two cases of congenital adenomatoid malformation in children in which mucinous epithelium lining parts of the cysts showed hyperplasia and intra-alveolar extension. These cases are compared with a case of bronchioloalveolar carcinoma in an adult associated with a long standing pulmonary cyst and similar mucous cell hyperplasia. We discuss the possible importance of this unusual hyperplasia.

\section{Case reports}

\section{CASE 1}

During investigation for isolated pulmonary valve stenosis a 6 month old boy was found to have multiple cysts within the right lower lobe, which compressed the mediastinum. A right lower lobectomy was performed. Examination of the resected lobe showed that it was largely replaced by multiloculated cysts, measuring from 0.5 to $4 \mathrm{~cm}$ in diameter, which communicated with the bronchi. There was a thin peripheral rim of unaffected lung.

Accepted for publication 22 December 1986
CASE 2

A 3 year old girl presented with recurrent respiratory infections. A chest radiograph showed left sided pulmonary cysts and mediastinal compression. A left lower lobectomy was performed. Multilocular cysts measuring up to $5 \mathrm{~cm}$ in diameter and communicating with the bronchi were present in the resected lobe. The remaining lung parenchyma was consolidated.

\section{CASE 3}

An 18 year old male athlete presented with slight haemoptysis and impairment of his exercise tolerance. A chest radiograph showed a left sided apical cyst, which was excised with a wedge of surrounding lung. Examination of the resected specimen showed a $6.5 \mathrm{~cm}$ diameter cyst with a trabeculated inner surface; white nodules, measuring up to $0.4 \mathrm{~cm}$ in diameter, were found in the adjacent lung.

\section{Material and methods}

All the specimens were fixed in formalin, those from cases 1 and 2 being inflated through the lobar bronchus. Representative blocks were taken from the specimens, and sections were stained by haematoxylin and eosin and elastic van Gieson. Mucin was identified by periodic acid Schiff and alcian blue high iron diamine stains.

\section{Histological findings}

CASES 1 AND 2

The walls of the cysts were formed by smooth muscle 
and elastic tissue, generally lined by bronchiolar type pseudostratified ciliated columnar and cuboidal epithelium. Direct communication with bronchioles and alveolar ducts was shown, the number of bronchioles appearing to be increased. Cartilage was not present in the cyst walls.

In both cases tufts of mucous cells lined parts of the cysts and extended outside the cysts to line adjacent alveoli (figs 1 and 2). Mucin stains showed that the bronchiolar type epithelium lining much of the cysts included some goblet cells containing sialomucin. The papillary tufts and intra-alveolar collections of mucous cells contained moderate amounts of both sialomucin and sulphomucin.

\section{CASE 3}

The cyst was lined by bronchiolar type epithelium with occasional mucous cell tufts similar to those seen in cases 1 and 2. Adjacent to the cyst there were collections of benign hyperplastic intra-alveolar mucous cells with small regular basal nuclei and a prominent

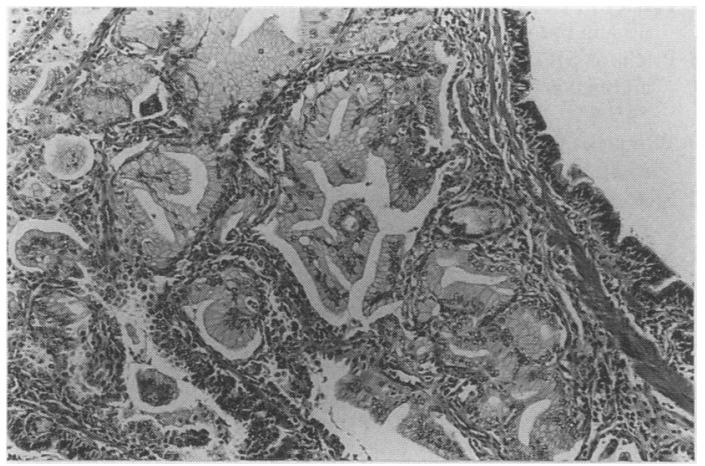

Fig 1 Case 2: tufts of mucous cells can be seen within alveolar spaces some distance from cyst. Note bronchiolar type of epithelium lining cyst. (Haematoxylin and eosin.)

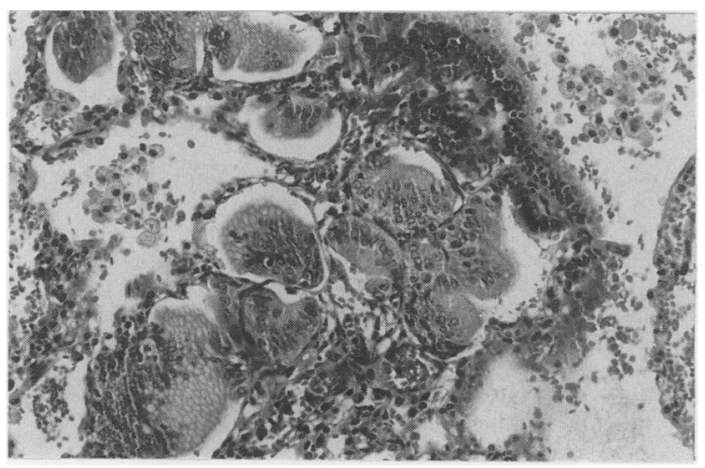

Fig 2 Case 1: higher magnification showing nests of columnar mucous cells filling alveoli. (Haematoxylin and eosin.)

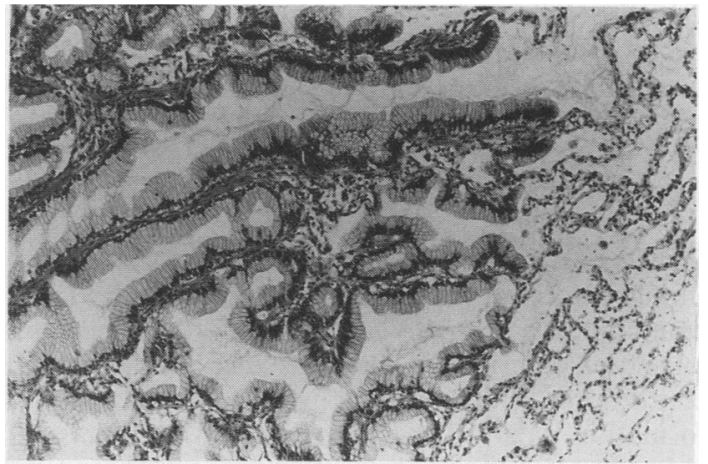

Fig 3 Case 3: benign mucous cells lining alveolar epithelium. (Haematoxylin and eosin.)

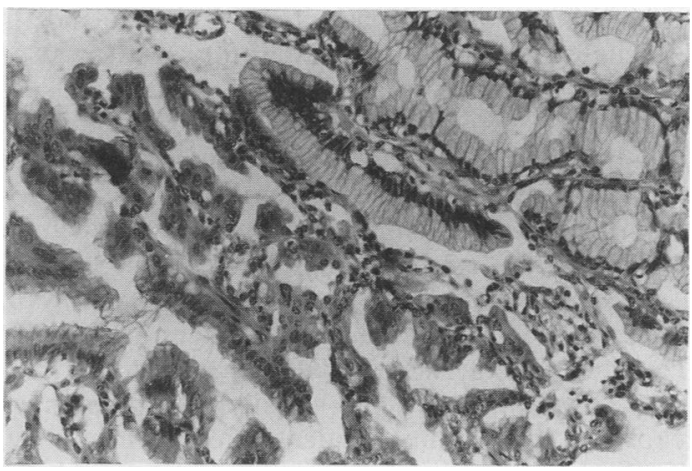

Fig 4 Case 3: close association exists between tumour (left) and benign hyperplastic mucous cells. (Haematoxylin and eosin.)

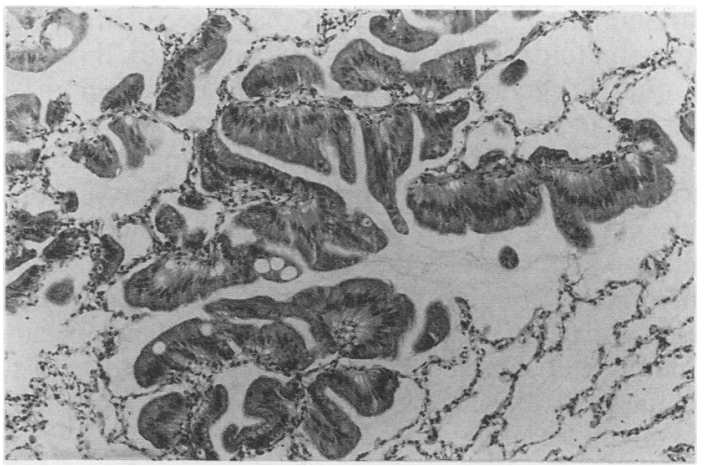

Fig 5 Case 3: bronchioloalveolar carcinoma; tumour cells replace alveolar epithelium. (Haematoxylin and eosin.)

pale cytoplasm. These contained large amounts of sialomucin and small amounts of sulphomucin (figs 3 and 4). Similar mucin was identified in the mucous cells in the cyst.

In addition, an adenocarcinoma of bronchioloalveolar type with a multifocal distribution was found in the lung surrounding the cyst (figs 4 and 5). 
Tumour cells were columnar with large uniform hyperchromatic basal nuclei and eosinophilic cytoplasm. Mucin stains showed small amounts of intracellular sialomucin close to the apical surface.

\section{Discussion}

Congenital cystic adenomatoid malformation is thought to sesult from failure of proximal airways to communicate normally with alveoli. ${ }^{10}$ Three types have been described. ${ }^{11}$ The three cases described here conform to the definition of cystic adenomatoid malformation type 1 . Type II consists of multiple small cysts lined by bronchiolar epithelium and interspersed with relatively normal alveolar structures. Type III appears solid owing to a complex of non-aerated flattened bronchiole like structures. Types II and III are usually associated with respiratory distress at or soon after birth.

The main features of cystic adenomatoid malformation type I are the presence of single or multiple cysts and bronchiole like structures lined by pseudostratified ciliated columnar and cuboidal epithelium interspersed by rows of goblet cells. ${ }^{12-16}$ Hyperplastic smooth muscle may be present in the cyst wall, but cartilage and inflammatory changes are absent. There may be other associated congenital abnormalities, as in our first patient, who also had pulmonary stenosis. Although most patients present in infancy, in some cases symptoms become apparent only in later life. ${ }^{17}$

In case 3 the cyst appeared to be long standing and the appearances did not suggest cystic change in a carcinoma. ${ }^{1819}$ The mucous cells seen in cystic adenomatoid malformation are similar to those of normal bronchial glands and surface epithelium ${ }^{20}$; our mucin studies confirm this similarity. The mucous cells may have either a metaplastic or hamartomatous origin. ${ }^{21}$ Our cases are unusual in that the mucous cells extended beyond the cysts to line adjacent alveoli. In cases 1 and 2 the hyperplasia was similar to that in case 3 but less florid. The intra-alveolar spread had a pattern similar to bronchioloalveolar carcinoma, but the malignant component could be distinguished from the hyperplasia morphologically and by mucin staining.

The implication of this finding is that the adenomatous component seen in case 3 represents a premalignant lesion. The presence of similar, though much less florid, hyperplasia in the other cases suggests that this change may begin at an early age. We have recently noted extensive areas of squamous epithelium in another case of cystic adenomatoid malformation type I, showing that other forms of metaplasia can occur in these cysts and supporting the suggestion that it represents a possible origin for squamous cell carcinoma. ${ }^{9}$ These observations suggest that cystic adenomatoid malformation carries a risk of malignant change and that early removal of such lesions is advisable.

We thank Mr P Goldstraw, Mr JCR Lincoln, Mr V Lynch, and Professor MX Fitzgerald for permission to publish clinical details of these patients and Rhodabe Khambatta for typing the manuscript.

\section{References}

1 Bauer S. Carcinoma arising in a congenital lung cyst. Diseases of the Chest 1961;40:552-5.

2 Korol E. The correlation of carcinoma and congenital cystic emphysema of the lungs. Report of ten cases. Diseases of the Chest 1953;23:403-11.

3 Huntington HW, Poppe JK, Goodman MJ. Carcinoma arising in a congenital cyst of the lung. Report of a case. Diseases of the Chest 1963;44:329-32.

4 Larkin JC, Phillips S. Carcinoma complicating cyst of lung. Diseases of the Chest 1955;27:453-7.

5 Bass HE, Singer E. Co-existing lobar adenocarcinoma and cystic disease of the lung. Ann Intern Med 1951;34:498-507.

6 Moersch HJ, Clagett OT. Pulmonary cysts. Journal of Thoracic Surgery 1947;16:179-94.

7 Hurley P, Corbishley C, Pepper J. Bronchioloalveolar carcinoma arising in longstanding lung cysts. Thorax 1985;40:960.

8 Prichard MG, Brown PJE, Sterrett GF. Bronchioloalveolar carcinoma arising in longstanding lung cysts. Thorax 1984;39: 545-9.

9 Womack NA, Graham EA. Epithelial metaplasia in congenital cystic disease of the lung. Am J Pathol 1941;17:645-53.

10 Spencer H. Pathology of the lung. 4th ed. London: Pergamon Press, 1985:79-130.

11 Stocker JT, Madewell JE, Drake RM, Congenital cystic adenomatoid malformation of the lung. Classification and morphologic spectrum. Hum Pathol 1977;8:155-71.

12 Landing BH, Dixon LG. Congenital malformations and genetic disorders of the respiratory tract. (Larynx, trachea, bronchi and lungs). Am Rev Resp Dis 1979;120:151-80.

13 Belanger R, La Fleche LR, Picard J-L. Congenital cystic adenomatoid malformation of the lung. Thorax 1964;19:1-11.

14 Kwittken J, Reiner L. Congenital cystic adenomatoid malformation of the lung. Pediatrics 1962;30:759-68.

15 Moncrieff MW, Cameron AH, Astley R, Roberts KD, Abrams LD, Mann JR. Congenital cystic adenomatoid malformation of the lung. Thorax 1969;24:476-87.

16 Miller RK, Sieber WK, Yunis EJ. Congenital adenomatoid malformation of the lung. A report of 17 cases and review of the literature. Pathol Annu 1980;15:387-407.

17 Avitabile AM, Hulnick DH, Greco MA, Feiner HD. Congenital cystic adenomatoid malformation of the lung in adults. Am J Surg Pathol 1984;8:193-202.

18 Anderson HJ, Pierce JW. Carcinoma of the bronchus presenting as thin-walled cysts. Thorax 1954;9:100-5.

19 Peabody JW, Rupnik EJ, Hanner JM. Bronchial carcinoma masquerading as a thin-walled cyst. American Journal of Roentgenology 1957;77:1051-4.

20 Lamb D, Reid L. Histochemical types of acidic glycoprotein produced by mucous cells of the tracheobronchial glands in man. J Pathol 1969;98:213-28.

21 Daroca PJ. Mucogenic cells of congenital adenomatoid malformation of lung. Arch Pathol Lab Med 1979;103:258-60.

Requests for reprints to: Dr BJ Addis, Department of Histopathology, Brompton Hospital, Fulham Road, London SW3 6HP, England. 